\title{
Impetus of urban horticulture on open spaces: case of Mutare City
}

\author{
Vitalis Basera ${ }^{1 *}$, Absai Chakaipa ${ }^{2}$, Phamella Dube ${ }^{3}$ \\ Department of Tourism and Hospitality management, Manicaland State University of Applied \\ Sciences, Zimbabwe ${ }^{1}$ \\ Department of Applied Statistics, Manicaland State University of Applied Sciences, Zimbabwe ${ }^{2}$ \\ Department of Agricultural Economics and Development Studies, Manicaland State University of \\ Applied Sciences, Zimbabwe ${ }^{3}$ \\ vitalisbasera@yahoo.com ${ }^{1 *}$, amchakaipa@gmail.com ${ }^{2}$, phamdube@gmail.com $^{3}$
}

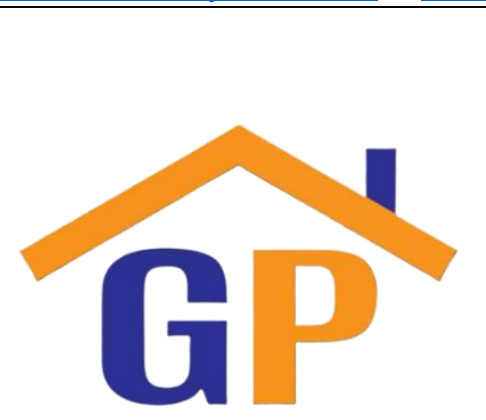

Article History

Received on 28 October 2020

Revised on 11 November 2020

Accepted on 16 November 2020

\begin{abstract}
Purpose: To understand the impetus of urban horticulture in the Mutare city with explicit motivation on low density areas.
\end{abstract}

Research methodology: The investigation was quantitative in nature, and used a random sample of urban farmers in Mutare city low density areas. The Statistical Package for Social Scientist (SPSS Version 23) was used to analyse data from the questionnaires.

Results: The results reveal that Mutare urban agricultural activities are driven by the need for food self-sufficient, income generation and utilisation of urban open spaces.

Limitations: The research had limitations on the sample size and also needed to factor in other multiple response questions.

Contributions: The findings are useful to urbanites, urban planners, developmental agents and authorities in the development of urban agriculture.

Keywords: Urban horticulture, Urban agriculture, Mutare, Impetus, Food security

How to cite: Basera, V., Chakaipa, A., Dube, P. (2020). Impetus of urban horticulture on open spaces: case of Mutare City. Journal of Social, Humanity, and Education, 1(1), 27-37.

\section{Introduction}

Zimbabwe's population is increasingly urbanised, and world over urban population is estimated to grow by $68 \%$ by 2050 , urban agricultural land will continue to be strained further to meet the nutritional needs of the growing population (FAO, 2015; UN Department of Economic and Social Affairs, 2019). Zimbabwe is facing an economic crisis, and was further worsened by COVID-19 pandemic. High inflation eroded disposable incomes of population and inflation reached a triple digit of $737 \%$ by June 2020 , unemployment is at above $80 \%$ and food prices increased by $750 \%$ (World Bank, 2020). Urban agriculture is a real solution to some of the challenges facing urban population and it is not a new phenomenon in major cities in Zimbabwe including Gweru, Bulawayo, Harare and Mutare. Agriculture is the backbone of Zimbabwe's economy and a major contributor to Gross Domestic Product in Zimbabwe (approximately 17\%) however chronic malnutrition remains a major challenge in the country due to a combination of reduced food availability caused by poor agricultural performance, lack of access to food due to high levels of poverty and poor food utilization (FAO, 2020).

Mutare city is one of the oldest cities in Zimbabwe on the eastern part of the country linking Zimbabwe to Mozambique and is the gateway to the sea. The city sits on 16500 hectares of land with an estimated population of 188243 people, 4662 low density housing units, 926 medium density housing units and 43620 high density housing units (City of Mutare, 2020). Most of urban agriculture in the city of Mutare is done in the medium and high-density suburbs. The advent of lockdown measures due to COVID-19 pandemic saw a massive increase in the urban horticulture activities in the city. Of interest was horticulture activities along Hobhouse stream which is flanked by densely populated locations of 
Hobhouse, Mushamukadzi and Matan to the West of the city. A lot of urban horticulture is practiced in the city of Mutare despite it being not sanctioned by the city local authority. Figure 1 shows the images from the Hobhouse stream; the green belt indicates where horticulture is being done along the stream and dominant crops grown in the area.

Figure 1: Green belt and crops

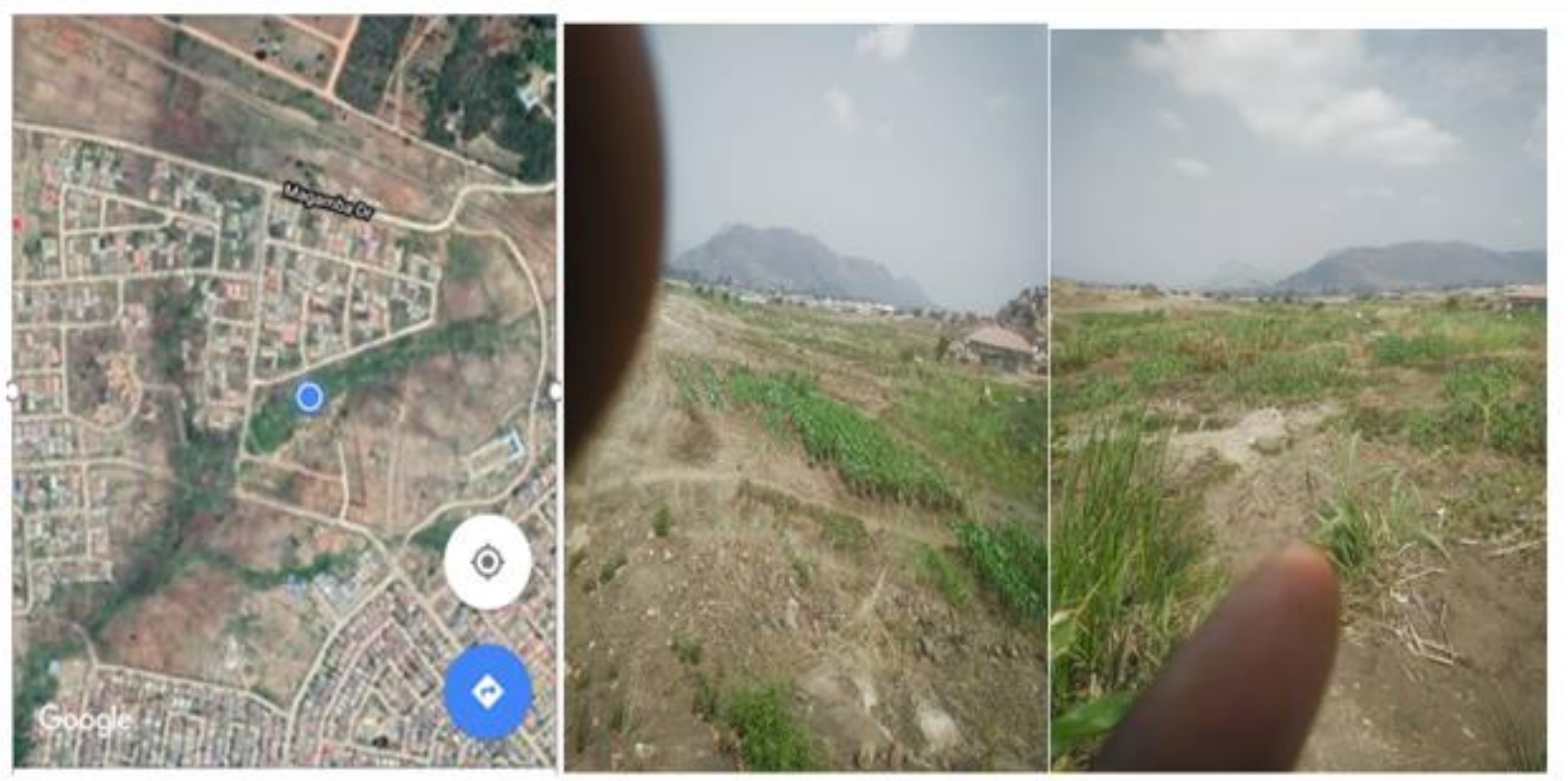

In 2020, Amao carried out an empirical review of the state of urban horticulture in cities across subSahara and concluded that governments in the different countries need the political will to actualise the benefits of urban horticulture with sensitisation of key stakeholders such as politicians, policy makers and urban residents. Danso, et al., (2014) in Ghana expressed the economic significance of urban vegetable farming and the need to enhance sustainability in urban horticulture by integrating it into the urban planning process and supported through policies which resonated with Eigenbrod and Gruda, $\underline{(2015)}$ investigation of urban vegetable for food security in cities.

In Zimbabwe urban agriculture had evolving since 1980 from colonial urban planning. Beacon, (2000) articulated urban agriculture in Harare, highlighting the colonial repression of urban planning not allowing urban dwellers to practice agriculture which had detrimental effects to residents' livelihoods despite the abundance of open fertile land. A number of investigations in Zimbabwe had been done on urban agriculture among them hazardous farming practices in urban areas, urban agriculture opportunities and urban agriculture as a food security strategy for urban dwellers, (Chaminuka \& Dube, 2017; Poverty Reduction Trust, 2019; Ziwenga, 2014; Mkhokheli, 2012; Gandawa, 2020). Gwetsayi, et. al. (2016) investigated Caritas project on urban horticulture for food security and livelihood restoration in Mutare and noted that the project improved food and nutrition security and restored livelihoods for the targeted poor urban dwellers.

There is no research that have been carried on the impetus of urban horticulture on open spaces in recent years taking into cognisance the economic and social challenges bedeviling urban residents. This research therefore seeks to close this gap by investigating the impetus of urban horticulture in the Mutare city with explicit motivation on low density suburbs after the COVID-19 pandemic outbreak.

\section{Literature review}

\subsection{Understanding urban agriculture}

After people migrated to urban areas in search of better living and modernity, they face the ills of urbanisation which include crime, unhealthy environment, unemployment, food insecurity and resort to urban agriculture for solutions (Amao, 2020; Edmondson, et al., 2020; Martin-Moreau \& Ménascé, 2019; RUAF, 2007). Urban agriculture is the growing of plants and the raising of animals for food and other uses within and around cities and towns, and related activities such as the production and delivery 
of inputs, processing and marketing of products (FAO, 2007). Mouget (2000) defined urban agriculture as located within (intra-urban) or on the fringe (peri-urban) of a town, a city or a metropolis, and grows or raises, processes and distributes a diversity of food and non-food products. Urban agriculture uses largely human and material resources, products and services found in and around urban area, and in turn supplies human and material resources, products and services largely to that urban area. Urban agriculture contributes to food security however in Zimbabwe it is not supported by any legal instrument and condemned in urban by-laws (Mbimba, 2000). Several laws in place view urban agriculture as responsible for environmental degradation and other bio diversity challenge- Regional Town and Country Planning Act (Chapter 29:12), Environment Management Act (Chapter 20:27) and city by laws (Mkhokheli, 2012, Chaminuka \& Dube, 2017; Ziwenga, 2014).

Urban agriculture is practiced on vacant land designated for urban expansion and city development owned by the city authorities or individuals. Urban agriculture practices vary from country to country and city to city and it can be divided into horticulture, aquaculture, animal husbandry, forestry and other farming production systems (Smit, Nasr, \& Ratta, 2001). Martellozzo, et al., (2014) presented three broad categories of urban agriculture practices, personal, community and commercial. Personal urban agriculture is usually done on household gardern (backyard, indoor) for subsistence. Community urban agriculture include gardens at schools, senior citizens open spaces designated to provide public food. Commercial urban agriculture is done in small urban farms (vacant lots/plots), indoor farms and vertical farms on commercial basis. Little (2019) used horticulture definition given by RUAF "horticulture is the extensive production of vegetables and fruits within urban areas. Horticulture can be practiced in containers, soilless (shallow-bed gardening and hydroponics), and aquaculture. Amao (2020) reffered horticultural crops as fruits, vegetables, spices, okra, beans and medicinal plants which are rich sources of vitamins, minerals and phytochemical. The horticulture produce are consumed alongside staple food to ensure balanced diet and prevent malnutrition. In Zimbabwe women represent an important portion of urban farmers since they tend to have most of the responsibility for feeding the households, while man tend to seek urban employment $(\mathrm{FAO}, 2020)$.

\subsection{Drivers to urban agriculture}

Urban agriculture is driven by a combination of factors linked to severe food crisis, failure of land reform program, worsening poverty, agriculture market failure, political and economic challenges due to failure of government economic policies (Mkhokheli, 2012; Chaminuka \& Dube, 2017; Gwetsayi, et al., 2016; Nwosisi \& Nandwani, 2018; Martin, 2018). Growing poverty, hunger and lack of formal employment opportunities have forced development of urban agriculture (Gondo, et al., 2017). Urban dwellers are taking urban agriculture as a way to move out of poverty, for individual food supply and urban food security (Chaminuka \& Dube, 2017). Urban horticulture on top of ensuring food security it ensures appropriate nutrition of the urban population. The urban area provides special opportunities to urban agriculture with growing demand for food, proximity to markets and availability of cheap resources such as urban organic waste and waste water have stimulated the development of diverse agricultural production system in and around cities (Danso, et al., 2014; FAO, 2007). Horticulture products are consumed while fresh and urban horticulture have reduced transport, storage costs and reduced the value chain so as that benefiting both the producers and consumers (Eigenbrod \& Gruda, 2015; Kennard \& Bamford, 2020).

\subsection{Impact of urban agriculture- horticulture}

If stakeholders like politicians, legislators, urban planners, land owners, entrepreneurs, producers and urban dwellers acting at national, local and international levels work for common purpose they can transform urban agriculture to contribute to food security, food safety and livelihoods (RUAF, 2020; FAO, 2020). Urban agriculture contributes to balanced diet of the urban dwellers (Amao, 2020). FAO, RUAF and other international organisations in different countries noted that urban and peri-urban horticulture played a role in enhancing vitamin and micronutrient supply for households in the urban areas especially in the poor households. Urban agriculture creates employment and increase incomes to purchase food thus ensuring food security (Gandawa, 2020; Gwetsayi, et al., 2016; Kawadza, 2019; ZEPARU, 2014; World Bank, 2020). In Ghana after the country's independence the government supported urban agriculture in "Operation Feed Yourself" program as a measure to mitigate food 
demand producing cabbages, lettuce, cauliflower, onions, pepper and tomato (Amao, 2020). The program in Ghana improved use of the urban land and improved food security. Urban horticulture improves access to ready fresh crops reach in essential micronutrients in poor households' diets. It also serves as a means to secure the livelihoods of urban population (Gandawa, 2020).

Urban agriculture impact on poverty reduction, environmental management and economic development in most developing countries (Edmondson, et al., 2020; Martin-Moreau \& Ménascé, 2019). Urban agriculture improves climatic factors, biodiversity, air quality and waste water management in urban areas (Smit, et al., 2001; Mouget, 2000). African cities can expand and achieve zero hunger through urban agriculture if technical and institutional support is rendered. Urban horticulture can give rise to urban greening, open space greening, reduction of noise and pollution (FAO, 2015). Beyond provision of livelihood and food, urban agriculture contributed to city buffer zone management, flood control thus supporting climate change adaptation strategies, land reclamation, land protection, resource recovery from waste urban greening and biodiversity management (Edmondson, et al., 2020; RUAF, 2020; FAO, 2015). Urban agriculture may function as an important strategy for poverty alleviation and social integration of disadvantaged groups with the aim to integrate them into urban network, provide them with decent livelihoods and prevent social problems (FAO, 2020; Kawadza, 2019). Urban agriculture creates business opportunities from small to medium enterprises in the value chain (ZEPARU, 2014; Gwetsayi, et al., 2016; Nwosisi \& Nandwani, 2018).

Cultivation close to major roads and railways as well as abandoned sites pose threats to of health hazards to consumers through contamination of the produce (FAO, 2007; Poverty Reduction Trust, 2019). It can contribute to increase in malaria as mosquitos can breed in irrigated gardens. Urban agriculture leads to water pollution through use of fertilisers and pesticides (Poverty Reduction Trust, 2019). Urban agriculture can increase the risk of erosion and stream siltation depending on the topography, soil type, original vegetation cover along the streams and the cultivation practices of the farmers (Danso, et al., 2014; Mbimba, 2000).

From literature it can be summed that urban agriculture is a vehicle for empowerment, self-reliance, income generation and sustainable use and management of natural resources. It ensures availability, accessibility and affordability of unprocessed and meaning full household food security. Regulated urban agriculture can minimize its negative impacts in urban areas.

\subsection{Challenges faced by urban farmers}

Urban agriculture faces a number of challenges that are underpinned on urban development planning. Lack of basic amenities such as water and waste have to be produced and managed in line with the economic, environmentally friendly and equitable sustainable management (FAO, 2007; Poverty Reduction Trust, 2019; Ziwenga, 2014). Higher land prices and urban pollution contracts urban horticulture (Eigenbrod \& Gruda, 2015). Lack of laws supporting integration of urban agriculture into land use planning, urban greening, urban habitat diversity, reduction in noise and pollution hinders urban agriculture (Ziwenga, 2014). Urban farmers face challenges from thieves, animals destroying their crops and lack of funding to improve their farming as observed in the investigations carried out in Gweru, Bulawayo, Harare and Mutare (Chaminuka \& Dube, 2017; Gwetsayi, et al., 2016; Kawadza, 2019; Ziwenga, 2014). FAO in 2007 summarised urban horticulture challenges into five broad challenges: lack of political and institutional recognition of urban agriculture, shortage of land and water for horticulture, lack of product quality due to poor production and crop protection management, low output due to low income and small-scale farming which lacks adequate inputs and shortage of market and poor vegetable preservation.

\section{Research methodology}

\subsection{Area of Study}

The city of Mutare is the fourth largest city in Zimbabwe with a population of about 184205 residents located in 19 wards (https://www.worldometers.info). Residential areas are divided into low density suburbs, medium, high density and peri-urban suburbs. Low and medium residential suburbs have more than $300 \mathrm{~m}^{2}$ area. The high-density suburbs have residential areas of usually between 150 to $300 \mathrm{~m}^{2}$. The peri-urban centers consist of plots, unoccupied municipal land as well as commercial farming. For 
this study Hob-house, Chikanga, Sakubva and Dangamvura were chosen purposively in order to reflect the diverse challenges that confront urban cultivators.

\subsection{Methodology}

Most of Mutare residents' practice urban agriculture at different levels and for varying reasons. Urban farming is usually done in the backyards or front yards, in allotment fields or gardens, in plots and farms or in municipality vacant spaces. Our targeted population was therefore resident of Mutare practicing urban horticulture in any land space within the municipality of Mutare. However, sampling the whole population was not feasible we therefore resorted to cluster sampling of high residential places (Best and Kahn, 1993). From the list of 19 wards, purposive sampling of 4 wards was conducted giving a percentage population of $20 \%$. The wards were chosen on basis that most people in high residential areas do cultivation outside their yards rendering them prone to use of municipality land. Thereafter a simple random sampling of 25 households from each ward, practicing agriculture at varying levels and on varying sites were then identified giving a total sample of 100 respondents. Response rate was $76 \%$.

The study uses both closed and open-ended questionnaire to ensure that factual information and opinions were gathered from the respondents. The Statistical Package for Social Scientist (SPSS Version 23) was used to analyse data from the questionnaires. Questionnaires were pre-coded and post coded for input into the statistical application.

\section{Results and discussions}

\subsection{An analysis by gender, age, residential area and employment status}

Out of 76 respondents surveyed, $46(60.9 \%)$ were females whilst $12(39.5 \%)$ were males. A frequency distribution by age group revealed that the majority of respondents came from the age groups 25-34 years (26.3\%), 35-44 years (27.6\%) and 45-54 years (19.7\%), a cumulative percentage of about $74 \%$. A frequency distribution by residential area revealed that the majority of respondents surveyed practice farming in Hobhouse area (44.8\%), Dangamvura area (18.4\%) and Chikanga (17.1\%), only a few respondents with a cumulative percentage of approximately $20 \%$ practice urban farming on the eastern part and near town as in table 1.

Table 1: Demographic distribution by residential area

\begin{tabular}{|ll|l|l|l|l|}
\hline & Frequency & Percent & Valid Percent & Cumulative Percent \\
\hline Valid & HOBHOUSE & 34 & 44.8 & 44.8 & 44.7 \\
MUSHAMUKAD & 4 & 5.3 & 5.3 & 50.0 \\
ZI & & & & 68.4 \\
DANGAMVURA & 14 & 18.4 & 18.4 & 85.5 \\
CHIKANGA & 13 & 17.1 & 17.1 & 96.1 \\
Neartown & 8 & 10.5 & 10.5 & 100.0 \\
Easterntown & 3 & 3.9 & 3.9 & \\
Total & 76 & 100.0 & 100.0 & \\
\hline
\end{tabular}

A demographic analysis by employment status revealed that out of the 76 respondents surveyed the majority were the employed (47.4\%) and the unemployed (39.5\%), only a minority are retired and unemployed as in table 2 .

Table 2: Demographic distribution by employment status

\begin{tabular}{|ll|l|l|l|l|}
\hline & & & & Cumulative \\
& & Frequency & Percent & Valid Percent & Percent \\
\hline Valid & EMPLOYED & 36 & 47.4 & 47.4 & 47.4 \\
& SELF_EMPLOYE & 30 & 39.5 & 39.5 & 86.8 \\
D & & & & \\
\hline
\end{tabular}




\begin{tabular}{|l|l|l|l|l|}
\hline UNEMPLOYED & 7 & 9.2 & 9.2 & 96.1 \\
retired & 3 & 3.9 & 3.9 & 100.0 \\
Total & 76 & 100.0 & 100.0 & \\
\hline
\end{tabular}

The demographic distribution results reveal that participation in horticultural activities cuts across all people irrespective of whether one is employed or not. A demographic distribution of House Ownership Status reveals that majority of people are house owners and also rent. Also, a graphical distribution of family size in adults reveals that the average number of adults is 2 per family. The same analysis of respondents revealed that a demographical distribution of family size in children reveals that the majority of families have two to four children per family.

The results revealed that much of the agricultural activities are being carried out in Hobhouse residential area. There are new residentials area under development in Hobhouse which include Matan, Mushamukadzi and there is plenty of open spaces, also the area integrates residential areas with periurban plots. The results on gender concurred with the findings of FAO that in Zimbabwe women represent an important portion of urban farmers since they tend to have most of the responsibility for feeding the households while men tent to seek formal employment. The results on employment status are not in line with Chaminuka \& Dube (2017), Gondo, et al., (2017) who posed that most of the urban famers are unemployed. The results revealed $9.2 \%$ of the farmers as unemployed thus the current urban farmers employed which is a new norm in urban farming. The family size of urban farmers is 5 or 6 person per household which depicts the need to provide food for the family, results did not reveal youth and young couples with no kids' participation in urban agriculture.

\subsection{Agricultural activities analysis}

An analysis of whether other family members participate in urban farming activities revealed that the majority of respondents responded Yes $(81.6 \%)$ as in table 3.

Table 3: A frequency distribution of participation of family members

\begin{tabular}{|ll|l|l|l|l|}
\hline & & Frequency & Percent & Valid Percent & Cumulative Percent \\
\hline Valid & NO & 14 & 18.4 & 18.4 & 18.4 \\
& YES & 62 & 81.6 & 81.6 & 100.0 \\
& Total & 76 & 100.0 & 100.0 & \\
\hline
\end{tabular}

On the rating of quality of produce, the majority of respondents rated themselves excellent or good, with a cumulative percentage of $77.9 \%$ as in table 4 .

Table 4: A frequency table on rate of quality of produce

\begin{tabular}{|ll|l|l|l|l|}
\hline & & Frequency & Percent & Valid Percent & Cumulative Percent \\
\hline Valid & Excellent & 16 & 21.1 & 21.1 & 21.1 \\
& Good & 43 & 56.6 & 56.6 & 77.6 \\
& Moderate & 16 & 21.1 & 21.1 & 98.7 \\
Bad & 1 & 1.3 & 1.3 & 100.0 \\
Total & 76 & 100.0 & 100.0 & \\
\hline
\end{tabular}

An analysis of where they sell their produce revealed that of the respondents who answered, $50 \%$ said that the produce is either sold in the neighborhood (14.5\%), organised market (11.8\%), to vendors $(10.5 \%)$ and local market $(7.9 \%)$, which on average a cumulative percentage of approximately $45 \%$. The majority of respondents $(60.5 \%)$ responded that they have a ready supply of produce throughout the year. The majority of respondents answered that there was an increase in agricultural activities during the Covid-19 lockdown period (52\%), whilst $48 \%$ responded of no increase in agricultural 
activities during the same period (Table 8). The respondents who responded yes to an increase mostly attributed this to abundant time (31.6\%) and increased produce demand $(9.2 \%)$. Of the respondents who responded No to an increase of activities attributed this mainly to low product demand at market coupled with sales decrease, shops and hardware to buy pesticides and other inputs closed during lockdown period as well as thefts.

An analysis of challenges faced by respondents doing urban farming around Mutare urban revealed that Covid-19 lockdown restrictions played a big role because most shops were closed from which they buy pesticides from and other inputs, market of produce was also reduced (14.5\%) as well as water crisis $(5.3 \%)$.

\subsection{Analysis of support system, labour, equipment and training}

On whether respondents in Mutare urban receive any support system within their local area in production of products, the majority responded no $(89.5 \%)$. Of the responded interviewed majority said they do not hire equipment for use in agriculture production (76.3\%), and the majority said they utilised people from Mutare (93.4\%). The majority of respondents said that they need training in agriculture skills $(69.7 \%)$. The response is line with majority of the respondents who said they did not receive any support system within their area. Of the respondents who said they need support system and training to complement agricultural activities said that most of the support they look forward to is mostly in terms of inputs including pesticides, training on agricultural activities.

A descriptive statistic reveals that of the 76 respondents in the survey on average they make a profit of about 80 United States dollars. The average number of adults and children is approximately 4 per family.

Table 4: Descriptive statistics on variables, profits and family size

Descriptive Statistics

\begin{tabular}{|c|c|c|c|c|c|c|c|c|c|c|c|}
\hline & $N$ & Range & Minimum & Maximum & Mean & Std. Deviation & Variance & \multicolumn{2}{|c|}{ Skewness } & \multicolumn{2}{|c|}{ Kurtosis } \\
\hline & Statistic & Statistic & Statistic & Statistic & Statistic & Statistic & Statistic & Statistic & Std. Error & Statistic & Std. Error \\
\hline age_res & 76 & 5 & 1 & 6 & 3.26 & 1.436 & 2.063 & .492 & .276 & -.534 & .545 \\
\hline profit_saleamount & 76 & $\$ 500.00$ & $\$ 0.00$ & $\$ 500.00$ & $\$ 78.6053$ & $\$ 117.36951$ & 13775.602 & 1.878 & .276 & 3.431 & .545 \\
\hline FAMILY_SIZEADULTS & 76 & 5 & 1 & 6 & 2.59 & 1.213 & 1.471 & .700 & .276 & -.218 & .545 \\
\hline FAMILY_SIZECHILDRE & 76 & 6 & 0 & 6 & 2.74 & 1.389 & 1.930 & .335 & .276 & -.601 & .545 \\
\hline Valid N (listwise) & 76 & & & & & & & & & & \\
\hline
\end{tabular}

The results revealed that the urban farmers do not receive support and do not hire equipment and this corroborates Ziwenga (2014) findings that urban agriculture is failing due to lack of support through laws supporting integration of urban agriculture into land use planning. The increase urban farming activities can be linked income generation as the results indicated an average profit of US\$80 from crop sales which is a lot money that can sustain an average family over a month. The problems of lack of funding to improve urban farming and theft was also observed in Gweru, Bulawayo, Harare by Gwetsayi, et al., (2016), and Kawadza (2019). The problems are buttressed by lack of support to the farmers as majority of respondents indicated that they do not get any kind of support in any way as shown in table 7.

Table 7: A frequency distribution table showing support system

\begin{tabular}{|ll|l|l|l|l|}
\hline & Frequency & Percent & Valid Percent & Cumulative Percent \\
\hline Valid & no & 68 & 89.5 & 89.5 & 89.5 \\
& yes & 8 & 10.5 & 10.5 & 100.0 \\
Total & 76 & 100.0 & 100.0 & \\
\hline
\end{tabular}

\subsection{Multiple response questions analysis}

A multiple response analysis is broken into two phases namely a frequency distribution per question, cross tabulations of multiple response questions against single response categorical variables (SPRVs) such as gender and multiple response critical analysis independence tests. The frequency and cross tabulations analysis are mostly done using SPSS. 


\subsection{Frequency analysis of multiple response questions}

An analysis of where agricultural activities are done revealed that most of the respondents said that they do these at their yards (47 out of 98) and at municipality vacant places (46 out of 98). On the question on which agricultural activities are done the majority of respondents said they mostly do beds vegetables and grains (maize). Of interest to this study and question is the number of people who do practice nursery seedling (6 out of 221 approximately 8.0\%) and traditional sweet potatoes (11 out of 221 responses, approximately $14.5 \%$ ), showing the need for selling purposes and also family consumption respectively. A minimal number of respondents do farming involving flowers, groundnuts and mushrooms this can be attributed to lack of farming knowledge, lack of resources and market of the products.

Table 15: Frequency distribution table on type of agricultural activities

\begin{tabular}{|ll|r|r|r|}
\hline & Count & Column N \% & $\begin{array}{c}\text { Column } \\
\text { Response } \% \\
\text { (Base: Count) }\end{array}$ \\
\hline FARMING_ACTPRAC & Beds_veg & 61 & $81.3 \%$ & $81.3 \%$ \\
& Beds_herbs & 2 & $2.7 \%$ & $2.7 \%$ \\
& Beds_fruits & 7 & $9.3 \%$ & $9.3 \%$ \\
& sweet_pot & 11 & $14.7 \%$ & $14.7 \%$ \\
& mushroom & 3 & $4.0 \%$ & $4.0 \%$ \\
NUrs_seedlings & 6 & $8.0 \%$ & $8.0 \%$ \\
& flowers & 4 & $5.3 \%$ & $5.3 \%$ \\
& groundnuts & 5 & $6.7 \%$ & $6.7 \%$ \\
& grains_maize & 54 & $72.0 \%$ & $72.0 \%$ \\
Total & 75 & $100.0 \%$ & $204.0 \%$ \\
\hline
\end{tabular}

A frequency table analysis (table 6) revealed that of the 221 responses given 73 out of $221(33 \%)$ said that they do their agricultural activities in summer and the remaining proportions almost distributed equally in other remaining three seasons. Most of the respondents prefer to practice agricultural activities in summer mostly because that's when it rains.

Table 6: Frequency distribution table on time of year for agricultural activities \$Q12 Frequencies

\begin{tabular}{|c|c|c|c|c|}
\hline & \multicolumn{2}{|c|}{ Responses } & \multirow{2}{*}{$\begin{array}{c}\text { Percent of } \\
\text { Cases }\end{array}$} \\
\hline & & $N$ & Percent & \\
\hline \multirow[t]{4}{*}{ AGRIC_SEASON ${ }^{\mathrm{a}}$} & Summer_DECJAN & 73 & $33.0 \%$ & $96.1 \%$ \\
\hline & Autu_MarchMay & 50 & $22.6 \%$ & $65.8 \%$ \\
\hline & Winter_JuneAug & 48 & $21.7 \%$ & $63.2 \%$ \\
\hline & Spring_SepNov & 50 & $22.6 \%$ & $65.8 \%$ \\
\hline Total & & 221 & $100.0 \%$ & $290.8 \%$ \\
\hline
\end{tabular}

a. Dichotomy group tabulated at value 1 .

On whether the respondents do irrigation or dry cultivation, the frequency distribution is almost equally distributed. A further analysis on source of water for irrigation revealed that most of the respondents said they mostly use pool water (38 out of 114 responses, from nearby rivers), while borehole and tap had 29 and 27 responses out of 114 responses respectively and a minority of 20 out 114 responses said they use sewer piped water 
Finally, on the question of why do the respondents do the agricultural activities the majority of respondents said they do practice agricultural activities mostly to augment family income and for sale with 56 and 43 responses out of a total of 120 responses.

\subsection{Cross tabulations analysis}

The variables in question are mostly Residential areas, Agricultural activities site, Irrigation source, Employment status and Agricultural activities purposes.

A cross tabulation analysis of residential area against Agricultural activities reveals that a majority of the respondents from Hobhouse and near town area [low density areas] area indicated that the do agricultural activities at municipal vacant places (66.7\% and 50\% respectively), of the respondents from Dangamvura and Chikanga areas indicated that they do mostly use their yards (approximately 53\%, $60 \%$ and $64.3 \%$ respectively).

A cross tabulation of residential area against irrigation water sources reveal that of the respondents from Hobhouse said they use pool and pipe (with $39 \%$ and $27 \%$ respectively). Of the Dangamvura respondents' surveyed majority said they use borehole and tap water (approximately 32\%) and approximately $21 \%$ respondent of using pool as their water source. In Chikanga area approximately $41 \%$ responded of using the pool mostly and $29.4 \%$ of using the borehole. Out of a total of 114 responses 38 responded of using the pool, 29 using the borehole and 27 of using the tap as their water sources.

A cross tabulation analysis in table 7 of employment status against agriculture activities purposes revealed that of the employed respondents answered that $44 \%$ do agriculture activities to augment family income and $36 \%$ for sale. In the same analysis of the unemployed respondents approximately $47 \%$ and $36 \%$ said it is for augmenting family income and for sale respectively.

Table 7: A cross tabulation table of frequencies of employment status and agriculture purposes

$$
\text { Q7 \$Q15 Crosstabulation }{ }^{\text {a }}
$$

\begin{tabular}{|c|c|c|c|c|c|c|}
\hline & & & & IC_PURPOS & & \\
\hline & & & $\begin{array}{c}\text { Urban_familyi } \\
\text { nco }\end{array}$ & Urban_sale & spport_utiliz & Total \\
\hline EMPLOYM_STATUS & EMPLOYED & Count & 24 & 20 & 11 & 55 \\
\hline & & $\%$ within Q7 & $43.6 \%$ & $36.4 \%$ & $20.0 \%$ & \\
\hline & & $\%$ within $\$$ Q15 & $45.3 \%$ & $50.0 \%$ & $52.4 \%$ & \\
\hline & SELF_EMPLOYED & Count & 25 & 19 & 9 & 53 \\
\hline & & $\%$ within Q7 & $47.2 \%$ & $35.8 \%$ & $17.0 \%$ & \\
\hline & & $\%$ within $\$$ Q15 & $47.2 \%$ & $47.5 \%$ & $42.9 \%$ & \\
\hline & UNEMPLOYED & Count & 4 & 1 & 1 & 6 \\
\hline & & \% within Q7 & $66.7 \%$ & $16.7 \%$ & $16.7 \%$ & \\
\hline & & $\%$ within $\$ Q 15$ & $7.5 \%$ & $2.5 \%$ & $4.8 \%$ & \\
\hline Total & & Count & 53 & 40 & 21 & 114 \\
\hline
\end{tabular}

Percentages and totals are based on responses.

a. There are not enough (less than 2) multiple response groups for pairing. Percentages are based on responses, but no pairing is performed.

b. Dichotomy group tabulated at value 1 .

\section{Conclusions}

The results reveal that Mutare urban agricultural activities are driven by the need for food self-sufficient, income generation and need for use of urban open spaces. The results indicated a need for support systems in terms of farming inputs and pesticides as well as training to be in place for it to sustain livelihoods at family level, community level as well as create employment opportunities through sales at local market. It can be concluded that the local authority is not supporting urban agriculture as they are not supporting the farming activities from by providing supporting by laws and organising farmers. The shortage of food and income in urban households in one of the key major drivers of urban 
agriculture as the families try to be food secure by embarking into farming. Unemployment is ever increasing in the country; urban agriculture if embraced can create employment to the population. There is need to support urban agriculture with inputs and training on sustainable agricultural methods that are a compatible to urban setting. Practicing urban agriculture in cooperative or groups can lead to economies of scale and better chances to secure support and lobby authorities for support. Nongovernmental organisation like Zimbabwe Poultry Association can assist urban farmers in livestock farming to strengthen agriculture value chain. There is need to extend government agriculture support schemes like Presidential inputs, Agriculture mechanization to the urban population since it has potential to contribute to national food security.

\section{Limitations and study forward}

The research had limitations on the sample size and also needed to factor in other multiple response questions. The sample size needs to be increased to at least 120 and survey farmers in other areas such as Weirmouth (peri-urban agriculture plots and such farmers are into multi agriculture activities including fruit, piggery and poultry production). Multiple research questions such as; Use of organic fertilisers, chemical (phosphatic) fertilizers or both in agriculture activities; Sources of information for agriculture farming such as professional consultant, veterinarians, state or local extension service workers, magazines, feed companies and representatives. More importantly, the analysis may need to make use of Multiple Response categorical variable (MRCV) in depth analysis. The current research only utilized single response categorical variables (SRCVs) and one multiple response categorical variable (MRCV) which does not capture association structures. The responses may be correlated, one cannot ignore the within-subject dependence and analyze the responses as if they were independent (Bilder \& Loughin, 2007). There is need to test for independence between two or more multiple response categorical variables and if they are dependent, what is the association structure?

\section{Acknowledgements}

The research was self-funded.

\section{References}

Amao, I. (2020). Urban Horticulture in Sub-Saharan Africa. In Open access peer-reviewed chapter. IntechOpen.

Best, J. W., \& Kahn, J. (1993). Research methods in education. New Age International Publisher, 6476.

Bilder, C. R., \& Loughin, T. M. (2007). Modeling association between two or more categorical variables that allow for multiple category choice. Communication in Statistics- Theory and Methods 36(1-4), 433-, 36: 1-4, 433-455.

Chaminuka, N., \& Dube, E. (2017). Urban agriculture as a food security strategy for urban dwellers: a case study of Mkoba residents in the city of Gweru, Zimbabwe. International Journal of Social Sciences, 3(2), 26-35.

City of Mutare. (2020). City of Mutare. Retrieved July 29, 2020, from www.nutarecity.co.zw

Danso, G., Hope, L., \& Drechsel, P. (2014). Financial and economic aspects of urban vegetable farming. In P. Drechsel \& B. Keraita (Eds.), Irrigated urban vegetable production in Ghana: Characteristics, benefits and risk mitigation Colombo: I. International Water Management Institute (IWMI)., 38-50.

Edmondson, J. L., Cunningham, H., Tingley, D. O., Dobson, M. C., Grafius, D. R., Leake, J. R., . . Cameron, D. D. (2020). The hidden potential of urban horticulture. Nature food, 1(3), 155 .

Eigenbrod, C., \& Gruda, N. (2015). Urban vegetable for food security in cities. A review. Agron. Sustain. Dev., 35, 483-498.

FAO. (2007). Profitability and sustainaibility of peri and urban agriculture. FAO.

FAO. (2015). Status of the World's Soil Resources. Rome: FAO.

FAO. (2020). Zimbabwe agriculture country report. Rome: Food and Agriculture Organization of the United Nations.

Gandawa, G. (2020). Urban Agriculture: Opportunities we refuse to see, White paper. Godfrey Ganadwa. 
Gondo, R., Madigele, P. K., Mogomotsi, G. E., Tokwe, T., Jeremiah, C., \& Chirefu, H. (2017). Sustainability of urban agriculture under economic and political instability in Karoi, Zimbabwe. Global Journal of advanced research, 4(2), 52-62.

Gwetsayi, R. T., Dube, L., \& Mashapa, C. (2016). Urban Horticulture for Food Security and Livelihood Restoration in Mutare City, Eastern Zimbabwe. Greener Journal of Social Sciences , 6(3), 56-64.

Kawadza, T. S. (2019). Role of urban agriculture. Harare: Herald.

Kennard, N. J., \& Bamford, R. H. (2020, August 27). researchgate.net. Retrieved August 27, 2020, from www.researchgate.net

Little, N. (2019). What is urban agriculture? Maryland: University of Maryland.

Martellozzo, F., Landry, J. S., Plouffe, D., Seufert, V., Rowhani, P., \& Ramankutty, N. (2014). Urban agriculture: a global analysis of the space constraint to meet urban vegetable demand. Environmental Research Letters, 9.

Martin, A. (2018). Vegetable Gardens in the City, Zimbabwe. Natural Resources Institute.

Martin-Moreau, M., \& Ménascé, D. (2019). Urban Agriculture: Another Way to Feed Cities. Field Actions Science Reports, 20.

Mbimba, B. (2000). Urban agriculture in Harare: between suspicion and repression. In: Bakker N, Dubbeling M, Gündel S, Sabel Koschella U, de Zeeuw H (eds) Growing cities, growing food: urban agriculture on the policy agenda, Deutsche Stiftung fu"rinternationale Entwicklung. Zentralstelle fu"r Erna"hrung und Landwirtschaft, Feldafing, 285-301.

Mkhokheli, S. (2012). Do Urban Community Gardens Matter? : The Case of Bulawayo Metropolitan province in Zimbabwe. Mediterranean Journal of Social Sciences, 3(9).

Mouget, L. J. (2000). Urban Agriculture: Definition, Presence, Potentials and Risks, and Policy Challenges. International Development Research Centre (IDRC).

Nwosisi, S., \& and Nandwani, D. (2018). Urban Horticulture: Overview of Recent Developments. In Urban Horticulture, Sustainable Development. Springer International Publishing AG, part of Springer Nature.

Poverty Reduction Trust. (2019). Hazardous Urban Farming practices: A stumbling block to Sustainable development. Harare: Poverty Reduction Trust.

RUAF. (2007). Urban Agriculture Policy: City of Bulawayo. RUAF foundation.

RUAF. (2020). Resource Center on Urban Agriculture and Food Security (RUAF) Foundation . Retrieved August 22, 2020, from www.ruaf.org

Smit, J., Nasr, J., \& Ratta, A. (2001). Producing food and fuel in urban areas. In Urban: Agriculture: Food, Jobs and Sustainable Cities. The Urban Agriculture Network, Inc.

UN Department of Economic and Social Affairs. (2019). World Population Prospects 2019. Rome: United Nations.

World Bank. (2020). Zimbabwe Overview. Washington, DC: The World Bank.

ZEPARU. (2014). Agro industries and value chain. Harare: Zimbabwe Econonic Policy and Research Unit.

Ziwenga, T. F. (2014). The viability of urban agriculture in reducing food insecurity in Gweru, Mkoba 19 suburb. Gweru: Midlands State University. 